NASA/TM-2003-211879

\title{
High Voltage TAL Erosion Characterization
}

David T. Jacobson

Glenn Research Center, Cleveland, Ohio 
Since its founding, NASA has been dedicated to the advancement of aeronautics and space science. The NASA Scientific and Technical Information (STI) Program Office plays a key part in helping NASA maintain this important role.

The NASA STI Program Office is operated by Langley Research Center, the Lead Center for NASA's scientific and technical information. The NASA STI Program Office provides access to the NASA STI Database, the largest collection of aeronautical and space science STI in the world. The Program Office is also NASA's institutional mechanism for disseminating the results of its research and development activities. These results are published by NASA in the NASA STI Report Series, which includes the following report types:

- TECHNICAL PUBLICATION. Reports of completed research or a major significant phase of research that present the results of NASA programs and include extensive data or theoretical analysis. Includes compilations of significant scientific and technical data and information deemed to be of continuing reference value. NASA's counterpart of peerreviewed formal professional papers but has less stringent limitations on manuscript length and extent of graphic presentations.

- TECHNICAL MEMORANDUM. Scientific and technical findings that are preliminary or of specialized interest, e.g., quick release reports, working papers, and bibliographies that contain minimal annotation. Does not contain extensive analysis.

- CONTRACTOR REPORT. Scientific and technical findings by NASA-sponsored contractors and grantees.
- CONFERENCE PUBLICATION. Collected papers from scientific and technical conferences, symposia, seminars, or other meetings sponsored or cosponsored by NASA.

- SPECIAL PUBLICATION. Scientific, technical, or historical information from NASA programs, projects, and missions, often concerned with subjects having substantial public interest.

- TECHNICAL TRANSLATION. Englishlanguage translations of foreign scientific and technical material pertinent to NASA's mission.

Specialized services that complement the STI Program Office's diverse offerings include creating custom thesauri, building customized databases, organizing and publishing research results ... even providing videos.

For more information about the NASA STI Program Office, see the following:

- Access the NASA STI Program Home Page at http://www.sti.nasa.gov

- E-mail your question via the Internet to help@sti.nasa.gov

- Fax your question to the NASA Access Help Desk at 301-621-0134

- Telephone the NASA Access Help Desk at 301-621-0390

- Write to: NASA Access Help Desk NASA Center for AeroSpace Information 7121 Standard Drive Hanover, MD 21076 
NASA/TM-2003-211879

AIAA-2002-4257

\section{High Voltage TAL Erosion Characterization}

David T. Jacobson

Glenn Research Center, Cleveland, Ohio

Prepared for the

38th Joint Propulsion Conference and Exhibit cosponsored by AIAA, ASME, SAE, and ASEE

Indianapolis, Indiana, July 7-10, 2002

National Aeronautics and

Space Administration

Glenn Research Center

February 2003 
Available from

NASA Center for Aerospace Information 7121 Standard Drive

Hanover, MD 21076
National Technical Information Service 5285 Port Royal Road Springfield, VA 22100 


\title{
High Voltage TAL Erosion Characterization
}

\author{
David T. Jacobson \\ National Aeronautics and Space Administration \\ Glenn Research Center \\ Cleveland, Ohio 44135
}

\begin{abstract}
Extended operation of a D-80 anode layer thruster at high voltage was investigated. The thruster was operated for 1200 hours at 700 Volts and 4 Amperes. Laser profilometry was employed to quantify the erosion of the thruster's graphite guard rings and electrodes at 0, 300, 600, 900 and 1200 hours. Thruster performance and electrical characteristics were monitored over the duration of the investigation. The guard rings exhibited asymmetric erosion that was greatest in the region of the cathode. Erosion of the guard rings exposed the magnet poles between 600-900 hours of operation.
\end{abstract}

\section{Introduction}

In 1999, the NASA Glenn Research Center began investigating Hall thrusters with specific impulses greater than the 1500 to 1700 seconds of state-of-theart thrusters. ${ }^{1-4}$ This increase in specific impulse over conventional xenon Hall thrusters was achieved by increasing discharge voltages from 300 Volts up to 1700 Volts. Operation at these elevated discharge voltages substantially increased the kinetic energy of the ions produced during thruster operation. At any discharge voltage, some small fraction of the ions accelerated by the thruster impinge upon the thruster itself, eroding critical components, eventually causing the thruster to wear out. While experiments have shown this experimentally, the effect of discharge voltages in excess of 500 Volts on thruster lifetime has not been comprehensively investigated.

Past experiments at lower discharge voltages include qualification testing of the SPT-100 thruster for over 7000 hours at Fakel, and over 5000 hours at JPL. Both of these tests were conducted at discharge voltages of 300 Volts. A similar test of the SPT-140, at a discharge voltage of 300 Volts, is also currently underway. 7 Published anode layer life tests include a 636 hour test conducted at a discharge voltage of 300 Volts using the D-55 thruster, ${ }^{8}$ and a 1000 hour test of the TAL-110 thruster operating at a discharge voltage of 350 Volts. $\quad$ A 1000 hour erosion characterization test of the SPT-type T-220 thruster was conducted at a discharge voltage of 500 Volts. $^{10}$ This investigation was the first published extended duration test of a Hall thruster at elevated discharge voltages. The results of each these tests confirmed that thruster erosion due to ion impingement determines thruster operational lifetime for both SPTtype and TAL-type Hall thrusters.
The objective of the current investigation was to evaluate the effect of high voltage operation on thruster erosion. Specifically, a D-80 anode layer thruster was operated at a discharge voltage of 700 Volts. A 700 Volt discharge voltage was selected because a previous performance investigation of the thruster demonstrated maximum thruster efficiency at discharge voltages between 500 and 800 Volts. $^{1}$ Furthermore, thruster efficiency was shown to increase linearly with thruster power. A 4 Amperes discharge current was selected for extended operation because this was the maximum value that could be achieved while maintaining the desired steady state thermal conditions. The anode efficiency and specific impulse at this operating point were $57 \%$ and 2625 seconds, respectively. While efficiency over $70 \%$ and specific impulse over 4000 seconds were demonstrated at higher discharge voltages and currents, high thruster temperature prohibited operation for extended periods of time. The thruster was operated for a total duration of 1200 hours in this investigation. Erosion of critical thruster components was evaluated every 300 hours. The results of this evaluation are presented.

\section{Apparatus and Procedure}

The D-80 was built under contract with Boeing Rocketdyne and was fabricated by their subcontractor, the Central Research Institute of Machine Building (TsNIMASH). The D-80 was capable of two-stage operation, but was operated in the single stage configuration for the erosion test. The performance test results indicated that singlestage performance was equivalent or better than twostage performance in the high voltage, high 
efficiency regime. Details of the thruster design and the performance data were previously described. ${ }^{1,11}$

This investigation was conducted in Vacuum Facility 12 at NASA Glenn Research Center. The chamber was 3 meters in diameter and 9 meters in length. The pumping capability was approximately $4.6 \times 10^{5}$ liters/sec calculated for xenon. The facility pressure during testing was approximately $1.0 \times 10^{-6}$ torr. The pressure was measured using an ionization gauge located on the chamber wall, in the same plane as thruster.

A laboratory power system consisting of commercially available power supplies was used to operate the discharge, cathode heater, keeper, inner and outer magnets. A PC based data acquisition system was used to record data throughout testing. Unattended operation was implemented using upper and lower limits set on the discharge current, which shut down the thruster in the event of an anomaly. Xenon propellant was supplied to the anode and cathode using a laboratory feed system consisting of two commercially available mass flow controllers. Constant volume flow calibrations were performed before and after the erosion test.

An inverted pendulum thrust stand, previously described in detail, was used to monitor thrust over the course of the investigation. ${ }^{12-13}$ To minimize the error resulting from zero drift, the inclination was adjusted once per 24 hours to the initial position and thrust recorded. The thrust stand calibration weights were cycled and a true zero was recorded each time the thruster was shutdown. While the infrequency of recording the zero and performing a calibration did increase the uncertainly in the thrust measurement, a performance investigation was previously conducted over a wide range of operating conditions. ${ }^{1}$ The thrust was measured in this investigation only as an indication of nominal thruster operation over the test duration.

Guard ring erosion was quantified after discrete periods of thruster operation. The thruster was operated in increments of 300 hours between voluntary shutdowns. Four test sequences were conducted for a total operating time of 1200 hours. Prior to the first sequence and at the conclusion of each 300 hour increment, the thruster was removed from the vacuum chamber and a laser line profiling measurement technique was used to quantify the guard ring erosion.

The laser line profiling technique was developed by Correlated Solutions, Incorporated for a previous Hall thruster erosion investigation. ${ }^{10}$ A cylindrical lens was used to create a plane of light, which was projected on the guard ring and anode electrode. At the intersection of the object and light plane, a line of light was produced. The object was viewed from a different angle with a standard charge coupled device (CCD) camera and the depth of the object was directly related to the position of the line in the camera's image. A telecentric lens was used on the $\mathrm{CCD}$ camera to minimize the effect of image magnification. A generic representation of the method is depicted in Figure 1. A calibration system was used to relate the location of the line in the image and its depth in space. The calibration also established the zero point and magnification for the range of the measurement. The coordinates of the thruster geometry images were resolved using the images collected during calibration. Each resolved image consisted of $480 \mathrm{x}-\mathrm{y}$ coordinates with an estimated error of less than $0.05 \mathrm{~mm}$.

The thruster was mounted to a rotation stage affixed to an aluminum frame. The laser was positioned so the laser line was perpendicular to the side of the thruster and the line crosses through the center of the thruster. This established a radial section of the ring being studied. A depiction of the apparatus is shown in Figure 2.

After the system was setup and calibrated, the thruster was rotated in $1^{\circ}$ increments and images of the inner guard ring and electrode were taken at each position. The apparatus was then reconfigured and images of the outer guard ring and electrode were collected in a similar fashion.

\section{$\underline{\text { Results and Discussion }}$}

Five sets of images of the thruster channel were collected. Each set includes 360 images of the inner geometry and 360 images of the outer geometry. The first set of images was collected before the engine was operated for the erosion test. The engine had been operated for 26 hours during the performance test before the initial images were collected. Subsequent images were collected after 300, 600, 900 , and 1200 hours of operation.

The profile of the thruster magnet pole, guard ring, $1^{\text {st }}$ and $2^{\text {nd }}$ stage anode electrodes are captured in each image. The thruster components are labeled in a sample image in Figure 3. All five of the profiles taken at each progressive time interval are included in the image. The profiles taken at 0 hours and 1200 hours are also labeled in Figure 3. While the sample image depicts only inner geometry, images of both the inner and outer portions of the channel were collected at each azimuthal position. The zero reference was located at the 12 o'clock position, shown in Figure 4. All angles are measured counter 
clockwise from the zero reference. The locations at which the lines of each feature are connected are a result of the coordinate reduction process, and not true geometric features of the thruster.

Images of the inner and outer geometry collected at the $0^{\circ}$ and $180^{\circ}$ positions, respectively, are presented in figures $5 \mathrm{a}$ and $5 \mathrm{~b}$. These figures reveal differences in the erosion around the circumference and also between the inner and outer geometry at the same angular location. Both the inner and outer ring profiles exhibit progressive erosion of the thruster components with time as expected. There are differences in the inner profiles taken at 0 and $180^{\circ}$. While the two inner profiles presented have a similar appearance for the first 300 hour increment, differences begin to appear over the later increments. The inner ring profile at the 0 degree location indicates that a larger amount of inner guard ring erosion had occurred compared to that at $180^{\circ}$. The 900 hour increment profile taken at $0^{\circ}$ indicates that the sufficient guard ring erosion occurred to expose the inner magnet pole to ion impingement causing inner magnet pole erosion. At the $180^{\circ}$ location, the inner guard ring erosion was low enough to protect the magnet pole for the entire duration of the experiment. While the magnitude of the differences in erosion are smaller, the same erosion phenomenon exists in the case of the outer guard ring. A larger amount of material was removed at the 0 degree location compared to that at $180^{\circ}$.

Figures $5 \mathrm{a}$ and $5 \mathrm{~b}$ also show a change in the $2^{\text {nd }}$ stage anode electrode geometry with time. The downstream tip of the electrode increased in length by approximately $0.5 \mathrm{~mm}$ over 1200 hours. This phenomenon was also evident on the surface of the electrode although to a lesser magnitude. The change was consistent around the circumference and present on both the inner and outer portions of the anode. A visual inspection of the hardware revealed that the anode surface was coated with a loosely affixed material, which appeared to be graphite. While the D-80 had a graphite anode, the surface appearance changed over time. The downstream tip appeared to have small cracks or separation of the surface, which caused the change in geometry seen in the profiles. It is possible that this condition was a result of long term, high temperature operation. While less likely, the loosely affixed material on the anode surface could have been caused by deposition. The material could have originated from the thruster's graphite guard rings or the facility. Because the guard rings and the anode were both made from graphite, determining the origin of the coating on the anode was not possible. No tests were conducted to definitely understand the phenomenon.
Using the images of the thruster geometry, the volume of material eroded over each 300 hour increment was calculated for each location around the circumference of the thruster channel. A numerical integration was performed for each degree, assuming a constant erosion profile over the arc length. The eroded volume calculation was performed for inner and outer guard rings and the inner and outer magnet poles. The region selected for the calculations is depicted in Figure 6 . The region selected for the magnet pole volume calculation was smaller than that used for the guard ring volume calculation. The magnet pole regions were restricted due to reflections of laser light and discontinuities caused by screw holes on the surface of the pole.

The calculated volumes of eroded inner and outer thruster components are provided in Table 1. The volume is a summation of the individual values calculated at each degree over each 300 hour time increment. The volume of graphite removed from the inner and outer guard rings are tabulated separately from the volume of metal removed from the poles. The volume of guard ring material removed was added to the volume of magnet pole material removed for the inner and outer geometry. These values of the total erosion are also presented in the Table. The volume of graphite that eroded from the inner and outer guard rings decreased with time, as the amount of graphite exposed to energetic ions decreased. As the guard rings eroded, the magnet poles were exposed to ion impingement, and the amount of magnet pole material eroded increased as expected.

The volume of graphite eroded from the inner and outer guard rings at each degree is presented in Figures 7 and 8, respectively. Similar plots of the metallic volume removed from the inner and outer magnet poles are presented in Figures 9 and 10. The eroded volume of the outer ring is fairly consistent around the circumference over the first 300 hours. One exception is an unexplained sharp decrease in eroded volume observed between $270^{\circ}$ and $310^{\circ}$. During subsequent operation intervals, the erosion became increasingly less consistent around the circumference. The eroded volume gradually decreased from $40^{\circ}$ to a minimum at $200^{\circ}$, then increased to $270^{\circ}$ where it remained fairly constant to $40^{\circ}$. Similar trends are exhibited in the case of the inner component erosion. This asymmetric guard ring erosion caused erosion of the inner magnet pole. Figure 9 shows the eroded volume of the inner pole, which occurred almost exclusively between $0^{\circ}$ to $80^{\circ}$ and $310^{\circ}$ to $360^{\circ}$. Figure 10 indicates that the outer magnet pole erosion was more consistent around the circumference than the inner pole. The sharp change 
in eroded volume between $270^{\circ}$ and $310^{\circ}$ observed in the outer guard ring erosion was also present in the outer pole erosion.

It is evident that the erosion rate was elevated in the vicinity of the cathode. For both the inner and outer rings, a larger volume of material was eroded between $40^{\circ}$ and $270^{\circ}$. A previous Hall thruster erosion test identified discharge chamber misalignment with respect to the magnetic field as the cause for asymmetric erosion. ${ }^{10}$ Misalignment of the channel caused elevated erosion on the inner portion of the channel, and lower erosion on the outer portion, which is not observed in this case. A previous TAL erosion study correlated the location of peak thruster erosion with local magnetic field minimums at locations between the electromagnets. ${ }^{14}$ In that investigation, the eroded volume was periodic with maximum erosion in regions of low radial magnetic field and minimum erosion in regions of high magnetic field strength. The D-80 erosion was not periodic, nor was the magnetic circuit design suspected as a cause for the asymmetric erosion.

In this case, the localized elevated erosion was likely caused by heavy particle impingement to which the other portions of the channel were not subjected. The particles are thought to be either ions generated in the cathode, or charge exchange ions created by collisions with neutrals escaping from the discharge or cathode. Simple kinetic theory calculations were made to understand the competing effects of the different particles. The path length for charge exchange was estimated using the background pressure and charge cross section for $700 \mathrm{eV}$ ions. ${ }^{15}$ The percentage of charge exchange ions was then calculated for the distance between the cathode and the region of elevated erosion. The calculation revealed that only a fraction of a percent of the discharge ions exchange charge. The calculation was also performed using an estimated neutral pressure at the exit of the cathode. At the elevated pressure, a more significant percentage of ions exchange charge. Because the ionization fraction of hollow cathodes is assumed to be small, the dominant effect could potentially be charge exchange ions due to cathode operation. A calculation using the charge exchange ion flux to the region of elevated erosion would need to be made to determine if these particles are responsible for the localized erosion phenomenon.

Cathode flow rate had an effect on thruster operation. Discharge current oscillations ranged from 0.8 to 1.4 Amperes. At cathode flow rates below $0.6 \mathrm{mg} / \mathrm{s}$ significantly larger discharge current oscillations were measured. Short duration, 5 Ampere oscillatory bursts were measured. These bursts were also observed visually as the cathode plasma increased in luminosity. The oscillatory operating mode was not observed when the cathode mass flow rate was increased to $0.8 \mathrm{mg} / \mathrm{s}$. A correlation between cathode operation, discharge current oscillations and erosion rate was discovered in a previous, long duration TAL experiment. $^{9} \quad$ In that experiment, the cathode operating mode was shown to have an effect on discharge current oscillations. Additionally, the measured erosion rate was 3 times higher over the operating interval with elevated discharge current oscillations. While unlikely that the cathode flow rate and corresponding discharge current oscillations caused the asymmetric erosion, there may be some correlation with the overall erosion rate. Additional experiments would be required to definitely understand the effect of cathode operation on thruster erosion.

The measured thrust remained constant over the 1200 hours of operation. The thrust produced was $118 \mathrm{mN}$ at the beginning and end of the experiment. The variation in thrust over the course of the experiment was less than $\pm 2 \%$, which is within the measurement accuracy. The erosion of the guard rings and magnetic pole had a negligible effect of the performance of the D-80 over 1200 hours of operation.

\section{$\underline{\text { Conclusions }}$}

A TAL thruster was operated for 1200 hours at 700 Volts to assess the effect of high voltage operation on thruster erosion. A discharge voltage of 700 Volts was selected because peak thruster efficiency was previously demonstrated between 500 and 800 Volts. Because efficiency was also found to increase with thruster power, the thruster was operated at the highest discharge current below the thruster's maximum desired temperature.

A laser profilometry method was used to quantify the guard ring and magnet pole erosion. Five surveys of the discharge channel were made at 0,300, 600, 900, and 1200 hours of operation. Both the inner and outer guard rings exhibited asymmetric erosion, which was elevated in the region of the cathode. Charge exchange collisions were suspected to have contributed to the localized erosion. While simple kinetic theory calculations were made to assess the plausibility of this scenario, additional experiments and calculations would be required to definitely determine the cause.

The measured thrust remained constant over the duration of the experiment, indicating that the erosion of the guard rings and pole pieces did not affect the 
performance of the device. While the guard ring's effectiveness was compromised between 600 and 900 hours, nominal thruster operation was maintained up to 1200 hours.

\section{$\underline{\text { References }}$}

1. Jacobson, D.T., Jankovsky, R.S., Rawlin, V.K., Manzella, D.H., "Performance of a High Voltage TAL,” AIAA-01-3777, July 2001.

2. Manzella, D.H., Jacobson, D.T., "High Voltage SPT Performance," AIAA-2001-3774, July 2001.

3. Jankovsky, R.S., et al., "NASA's Hall Thruster Program," AIAA-01-3888, July 2001.

4. Hofer, R.R., Peterson, P.Y., Gallimore, A.D., "A High Specific Impulse Two-Stage Hall Thruster with Plasma Lens Focusing," IEPC-01-036, October 2001.

5. Day, D., Maslenniov, N., Randolph, T., Rogers, W., "SPT-100 Subsystem Qualification Status," AIAA-96-2713, July 1996.

6. Garner, C.E., Brophy, J.R., Polk, J.E., Pless, L.C., "A $5730 \mathrm{Hr}$ Cyclic Endurance Test of The SPT-100,” AIAA-95-2667, July 1995.

7. Spanjers, G.G., et al., "The USAF Electric Propulsion Research Program," AIAA-3146, July 2000.
8. Garner, C.E., et al., "Experimental Evaluation of Russian Anode Layer Thrusters," AIAA-943010, June 1994.

9. Semenkin A.V., et al., "Development program and preliminary results of the TAL-110 thruster," AIAA-99-2279, June 1999.

10. Mason, L.S., Manzella, D.H., "1000 Hours of Testing on a 10 Kilowatt Hall Effect Thruster," AIAA-01-3773, July 2001.

11. Butler G.W., et al., "Multi-Mode High Specific Impulse Hall Thruster," AIAA-2000-3254 July 2000.

12. Haag, T.W., Manzella, D.M., "RHETT/EPDM Performance Characterization." IEPC-97-107, August 1997.

13. Jacobson, D.T., Jankovsky, R.S., "Test Results of a 200 W Class Hall Thruster," NASA/TM-1999-209449.

14. Marrese, C., et al., "Analysis of Anode Layer Thruster Guard Ring Erosion," IEPC-95-196, September 1995.

15. Pullins, S., et al., "Ion Dynamics in Hall Effect and Ion Thrusters: $\mathrm{Xe}^{+}+\mathrm{Xe}$ Symmetric Charge Transfer," AIAA 2000-0603, January 2000. 
Table 1: Volume of eroded material from inner and outer thruster geometry.

\begin{tabular}{|c|c|c|c|c|c|c|}
\hline Hours & $\begin{array}{c}\text { Inner } \\
\text { Graphite } \\
\left(\mathrm{mm}^{3}\right)\end{array}$ & $\begin{array}{c}\text { Inner Pole } \\
\text { Metal } \\
\left(\mathrm{mm}^{3}\right)\end{array}$ & $\begin{array}{c}\text { Inner Total } \\
\left(\mathrm{mm}^{3}\right)\end{array}$ & $\begin{array}{c}\text { Outer } \\
\text { Graphite } \\
\left(\mathrm{mm}^{3}\right)\end{array}$ & $\begin{array}{c}\text { Outer Pole } \\
\text { Metal } \\
\left(\mathrm{mm}^{3}\right)\end{array}$ & $\begin{array}{c}\text { Outer Total } \\
\left(\mathrm{mm}^{3}\right)\end{array}$ \\
\hline 300 & 319 & 31 & 350 & 528 & -1 & 527 \\
\hline 600 & 122 & -3 & 119 & 358 & 37 & 395 \\
\hline 900 & 72 & 22 & 94 & 200 & 143 & 343 \\
\hline 1200 & 53 & 78 & 131 & 120 & 353 & 473 \\
\hline
\end{tabular}

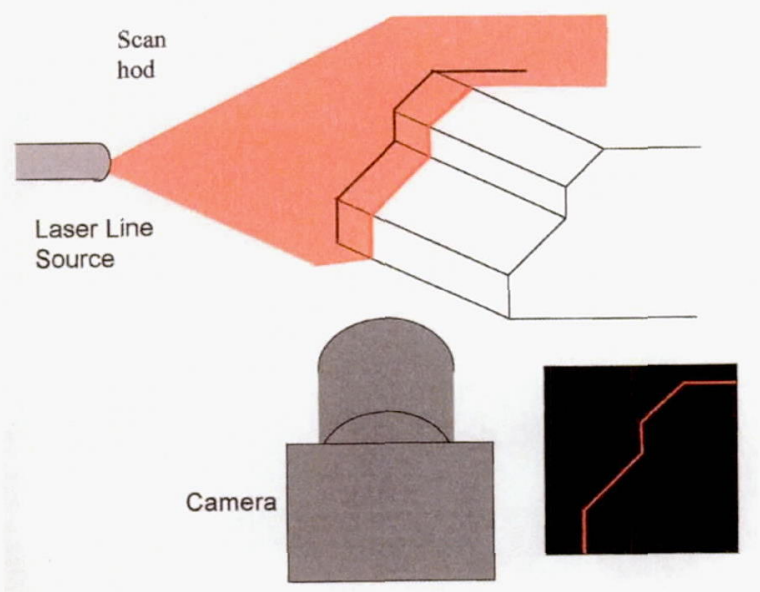

Figure 1: Generic representation of laser line profiling measurement method employed.

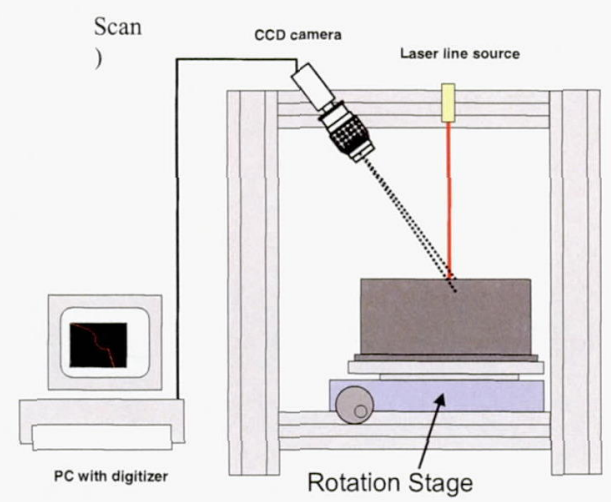

Figure 2: Schematic of the circumferential measurement apparatus. 


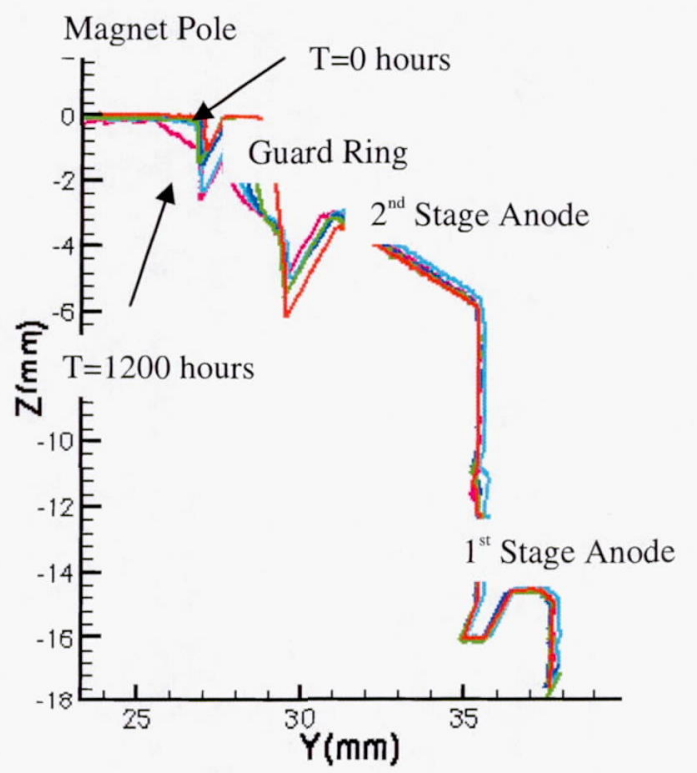

Figure 3: Sample image with geometric features of D-80 Hall thruster labeled.

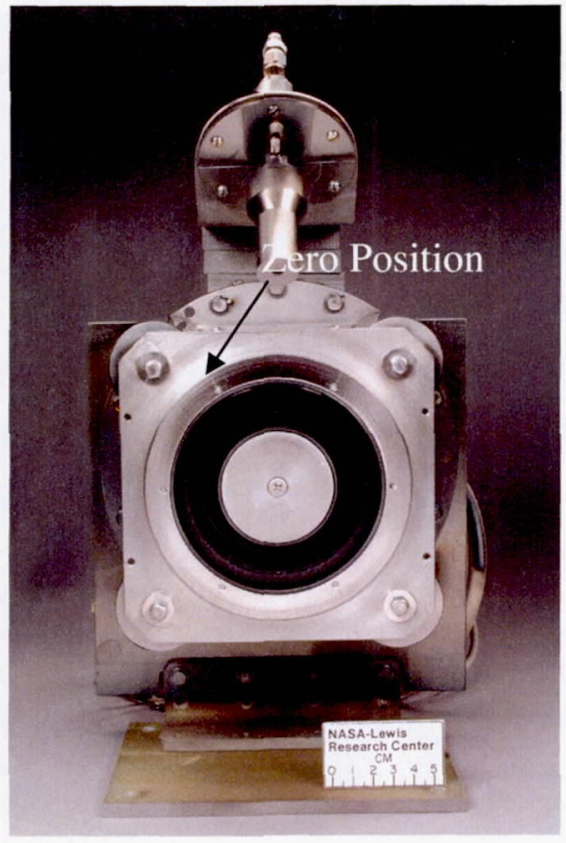

Figure 4: Zero position denoted on the D- 80 Hall thruster used in the erosion investigation. 

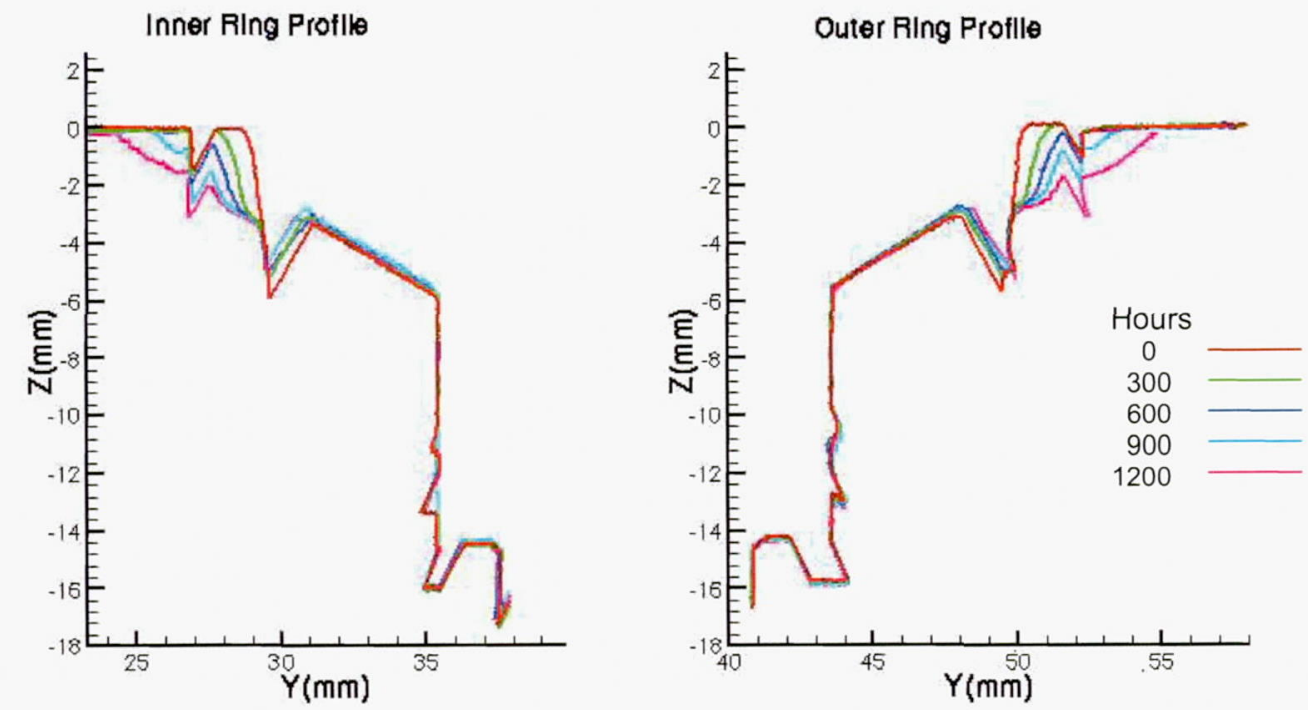

Figure 5a: Axial coordinate versus radial coordinate for magnet pole/anode/guard ring profile measured at 0,300 , $600,900,1200$ hours. $\left(0^{\circ}\right.$ azimuthal location $)$
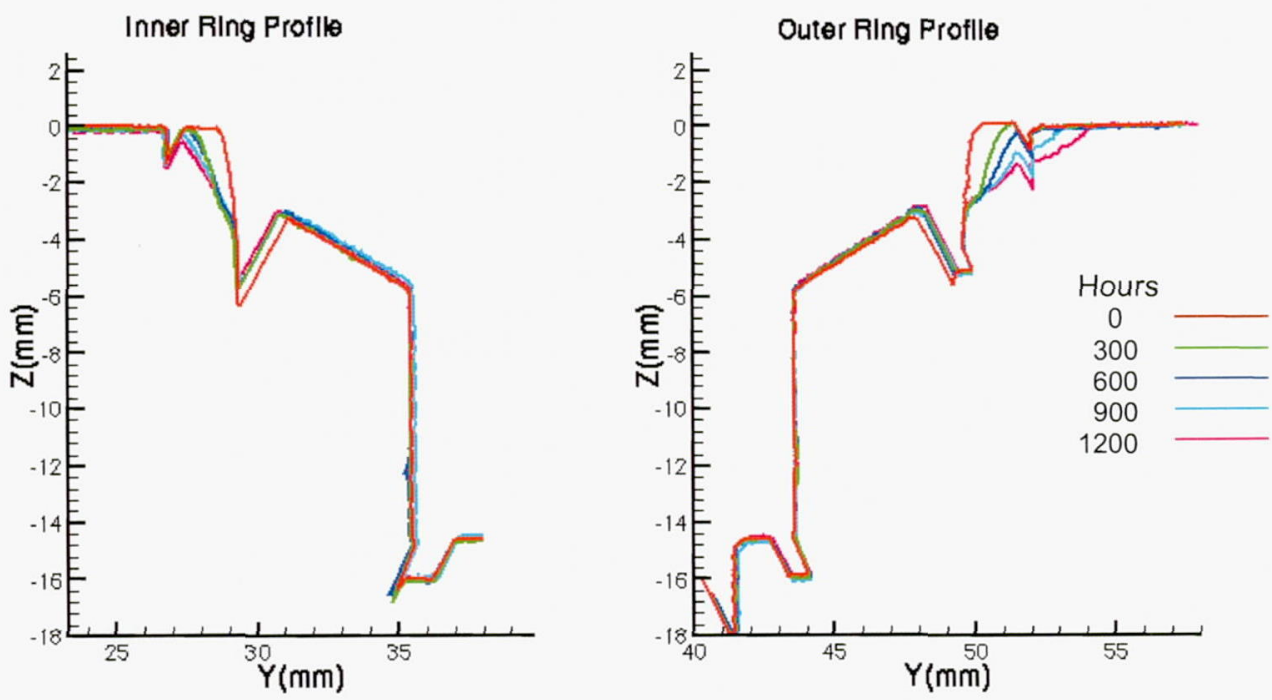

Figure 5b: Axial coordinate versus radial coordinate for magnet pole/anode/guard ring profile measured at 0,300 , $600,900,1200$ hours. ( $180^{\circ}$ azimuthal location) 

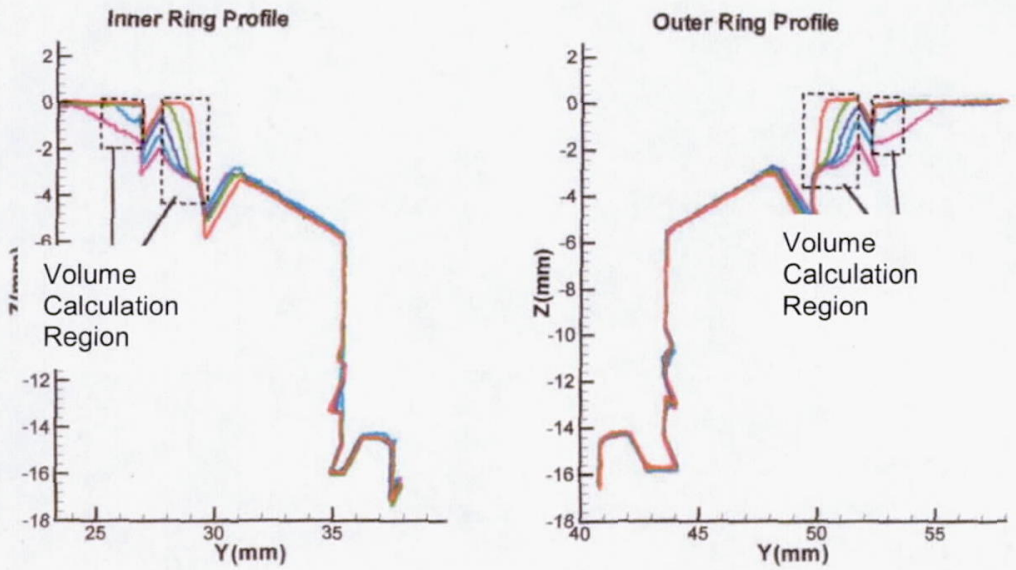

Figure 6: Region selected for volume calculation of eroded material.

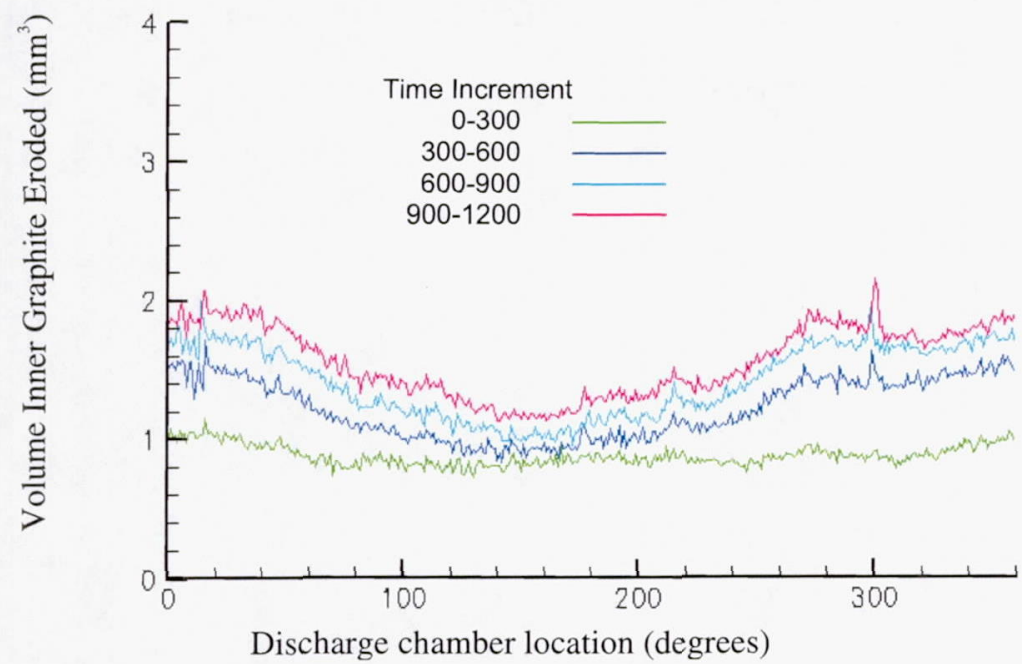

Figure 7: Volume of inner guard ring graphite removed at azimuthal locations between 0-360 degrees.

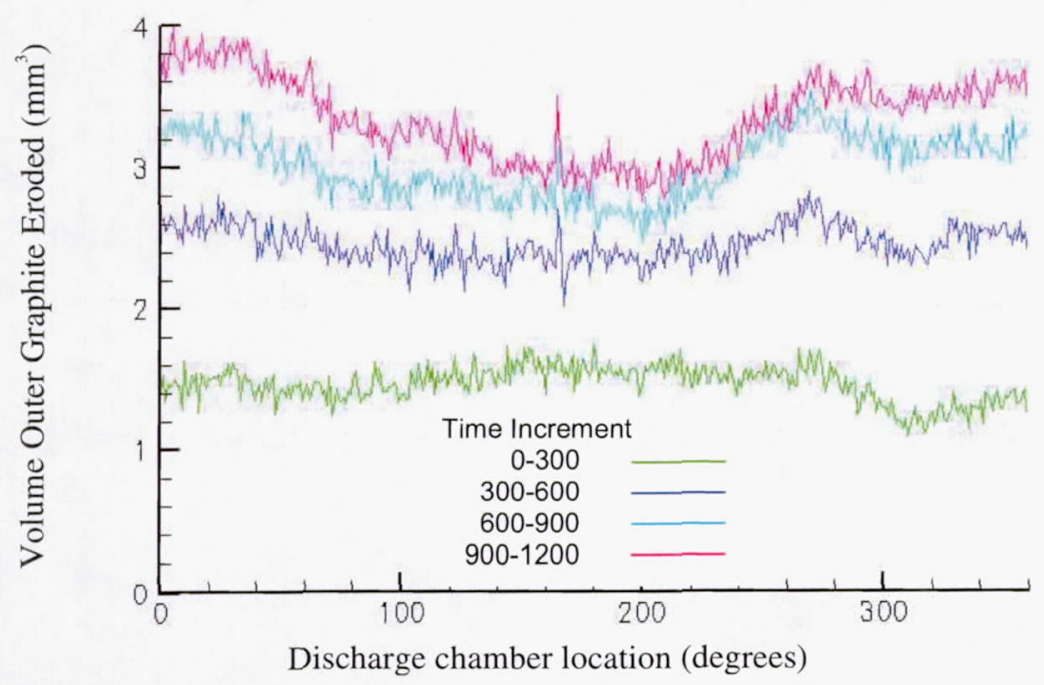

Figure 8: Volume of outer guard ring graphite removed at azimuthal locations between 0-360 degrees. 


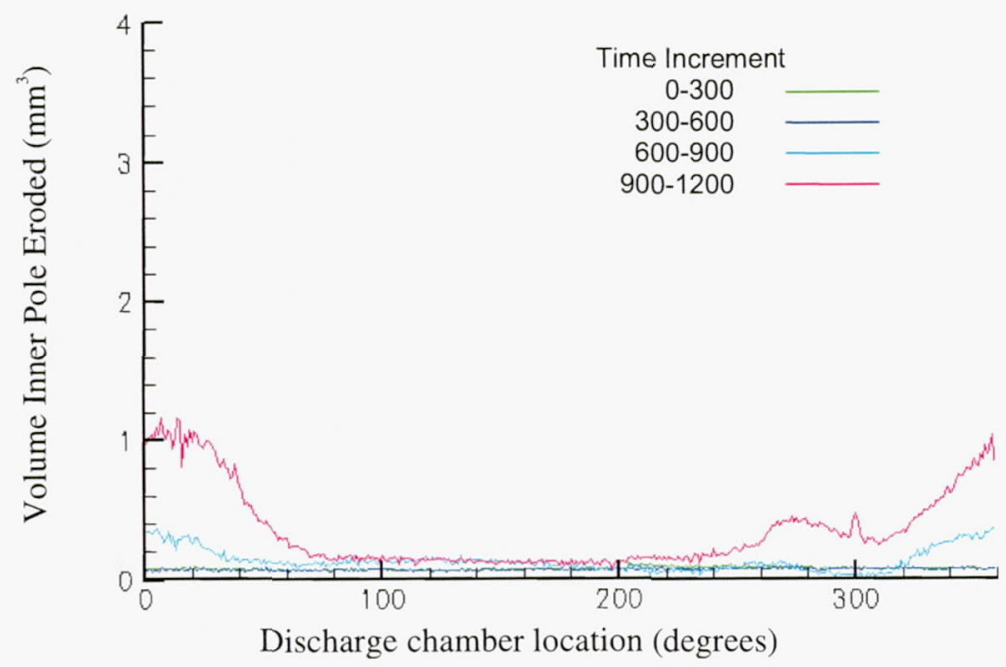

Figure 9: Volume of inner magnet pole removed at azimuthal locations between 0-360 degrees.

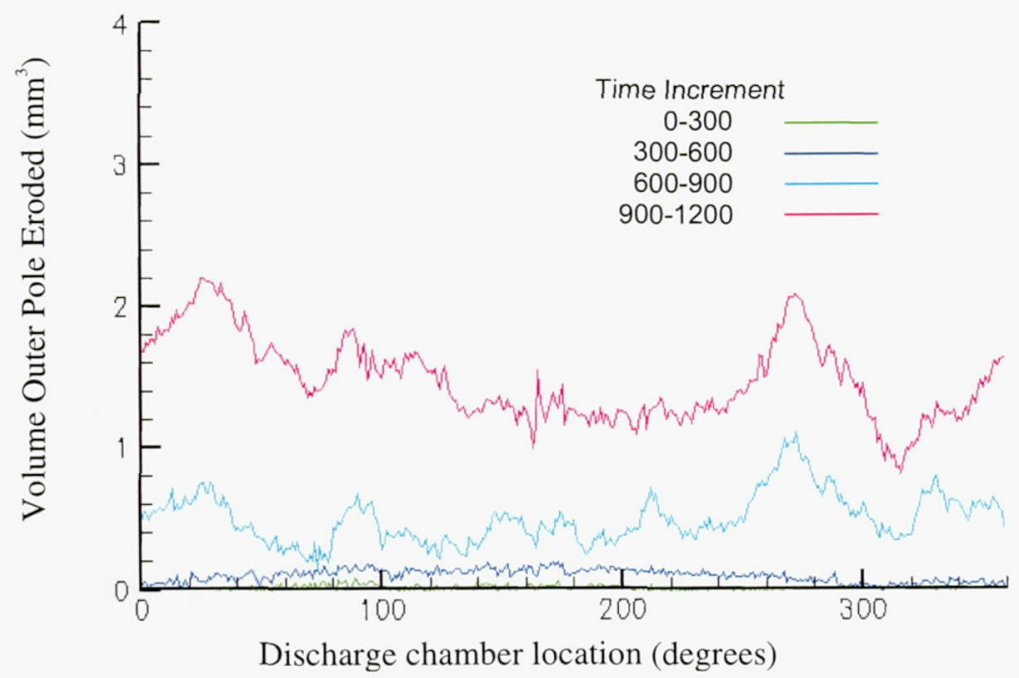

Figure 10: Volume of outer magnet pole removed at azimuthal locations between 0-360 degrees. 


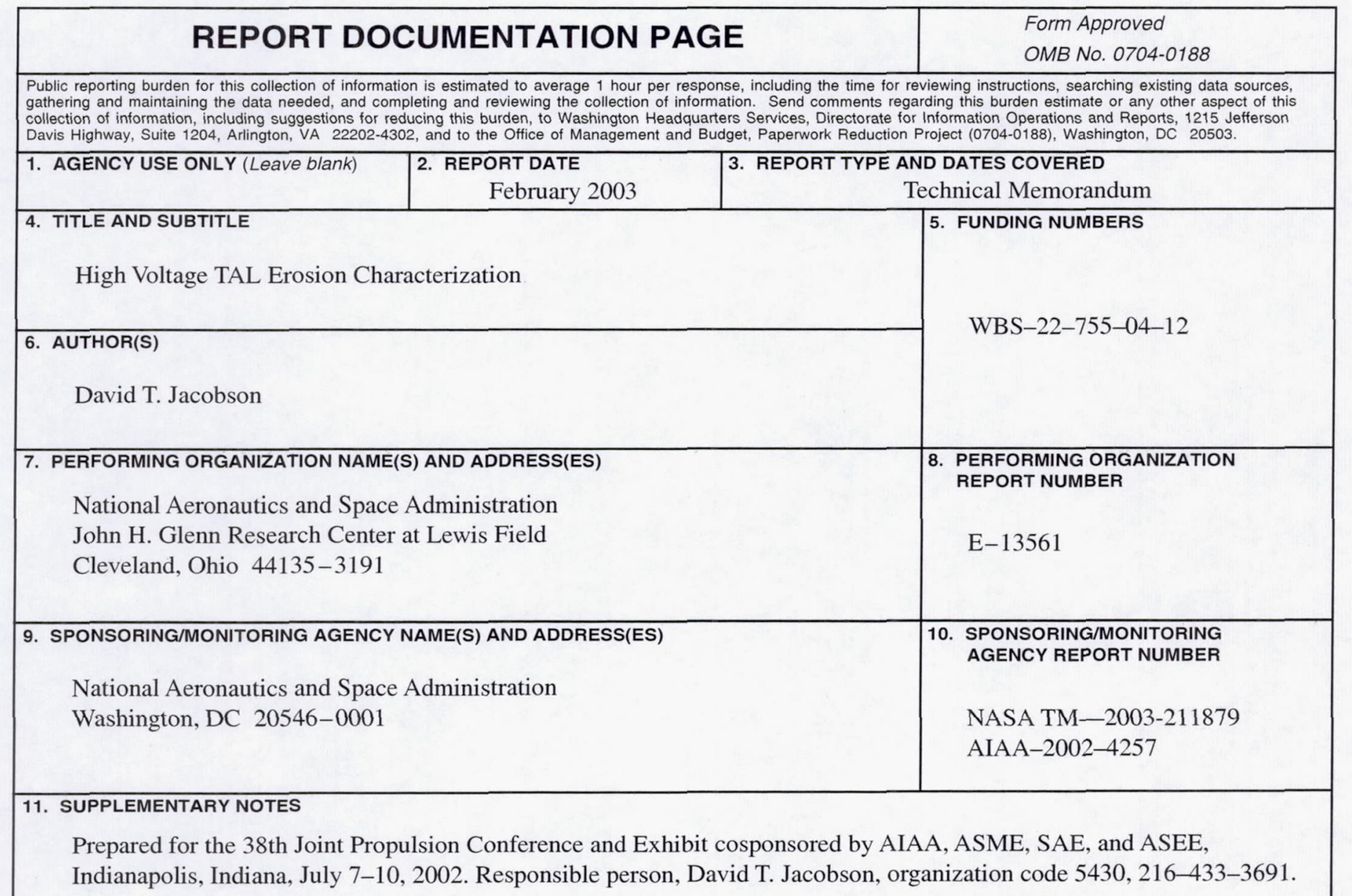

12a. DISTRIBUTION/AVAILABILITY STATEMENT

12b. DISTRIBUTION CODE

Unclassified - Unlimited

Subject Category: 20

Distribution: Nonstandard

Available electronically at http://gltrs.grc.nasa.gov

This publication is available from the NASA Center for AeroSpace Information, 301-621-0390.

13. ABSTRACT (Maximum 200 words)

Extended operation of a D-80 anode layer thruster at high voltage was investigated. The thruster was operated for 1200 hours at 700 Volts and 4 Amperes. Laser profilometry was employed to quantify the erosion of the thruster's graphite guard rings and electrodes at $0,300,600,900$, and 1200 hours. Thruster performance and electrical characteristics were monitored over the duration of the investigation. The guard rings exhibited asymmetric erosion that was greatest in the region of the cathode. Erosion of the guard rings exposed the magnet poles between 600 to 900 hours of operation.

\section{SUBJECT TERMS}

Electric propulsion; Electrostatic thruster; Spacecraft propulsion

15. NUMBER OF PAGES

16. PRICE CODE

\begin{tabular}{|c|c|c|}
\hline $\begin{array}{c}\text { 17. SECURITY CLASSIFICATION } \\
\text { OF REPORT } \\
\text { Unclassified }\end{array}$ & $\begin{array}{c}\text { 18. SECURITY CLASSIFICATION } \\
\text { OF THIS PAGE } \\
\text { Unclassified }\end{array}$ & $\begin{array}{c}\text { 19. SECURITY CLASSIFICATION } \\
\text { OF ABSTRACT } \\
\text { Unclassified }\end{array}$
\end{tabular}

